\title{
Evaluating the Local Climate Impacts Profile Tool for Assessing Local Impacts of Extreme Weather Events
}

\author{
Annika Carlsson-Kanyama ${ }^{1}$ and Kristina Blennow ${ }^{2}$ \\ ${ }^{1}$ Swedish Defence Research Analysis, 16490, Stockholm, Sweden \\ ${ }^{2}$ Department of Landscape Architecture, Planning and Management, Swedish University of Agricultural Sciences (SLU), SE-230 53 Alnarp, Sweden
}

\begin{abstract}
The climate change adaptation tool Local Climate Impacts Profile (LCLIP), developed and previously widely used in the UK, was systematically evaluated in terms of its transferability to Sweden and its usefulness as a catalyst for awareness-raising and action with respect to climate change adaptation. The tool includes scoping, media trawl, interviews and reporting and was applied in three Swedish municipalities. It was found that after some adjustment, the tool can be applied successfully under Swedish conditions. The municipalities involved found the results useful for stimulating local adaptation work. However, the municipalities concluded that LCLIP is primarily a beginner's tool that can be applied at a low cost and that other, more costly investigations on vulnerability to extreme weather typically need to be conducted for successful adaptation to climate change at municipal level. An advantage of the LCLIP tool is that it involves civil servants from all departments in the municipality and thus the resulting vulnerability discussions also involve departments dealing with 'soft' issues, such as administration and care.
\end{abstract}

Keywords: Local climate impacts profile; UKCIP; Swedish municipalities; Vulnerability

\section{Introduction and Aim}

Climate change is often recognised as one of the greatest challenges of our time. Without further commitments and action to reduce greenhouse gas emissions, the world is likely to warm by more than $3^{\circ} \mathrm{C}$ above the preindustrial climate, with unprecedented heat waves, severe droughts and major floods [1]. According to Burton [2], a lack of adaptation is already apparent today and the problem will increase as the climate continues to change. Many of the measures needed to adapt to specific climate change risks have to be taken locally [3].

Tools and methods for adapting to climate change are frequently presented and discussed in the literature, but climate change adaptation means different things to different authors. For example, Hanak and Lund [4] call measures such as underground water storage and water conservation for adaptation tools, Shepard et al. [5] see a need for a GIS-based approach to quantify potential changes in storm surge risk due to sea level rise, Spicket et al. [6] view a Health Impact Assessment as an essential adaptation tool and Baard et al. [7] call for socioeconomic scenarios for evaluating different options concerning preservation of a groundwater aquifer in the light of climate change. Thus tools and methods have been taken to include anything that helps society develop appropriate adaptation strategies and any concrete measure that will help society cope with the impacts of climate change once the planning stage is over. Examples of adaptation tools can be found e.g. on the United Kingdom Climate Impacts Programme [8] website [9] and in a manual developed by the United Nations Framework Convention on Climate Change [10]. In the literature, tools and methods for adaptation are suggested, with or without first being tested together with/on stakeholders such as employees of various departments in municipalities and regions, where much adaptation is planned and implemented. Examples of tools and methods proposed without prior testing with stakeholders include those described by Shepard et al. [5] and Holsten and Kropp [11]. Tools and methods that have been tested with stakeholders include those by e.g. Dai et al. [12], who tested a tool for reflexive learning about climate change adaptation called the Climate Learning Ladder in two regions, Mongolia and the EU, and Debels et al. [13], who tested an index for usefulness of adaptation practices in a region in Chile. However, only a few of these studies contain a systematic evaluation of stakeholder experiences from using the tools and methods, examples being Jonsson et al. [14], who used tools for conducting vulnerability assessments in two Swedish municipalities, and Albert et al. [15], who used a framework for participative scenariobased landscape planning in a German community.

The perception of having experienced climate change has recently been shown to significantly influence adaptation to climate change [16]. Therefore, collecting and disseminating information on climate change and its effects has been suggested as a strategy to increase perceptions of having experienced climate change, and hence encourage people to consider the need to take adaptive measures [16-18]. A tool aimed at creating knowledge about current impacts of weather and climate, thereby raising awareness of potential local deficits in adaptation, has been developed by UKCIP. Application of the tool, which is called the Local Climate Impacts Profile (LCLIP), is designed to promote understanding of current impacts and vulnerability to weather and climate in an organisation, thereby catalysing further awareness and action [8]. Furthermore, the tool is meant to demonstrate the extent to which the authority, community or organisation is prepared and able to respond now [19]. In this way, the tool is meant to be useful with respect to the development of planning policies and awareness raising and, in its country of origin, to meet the requirements of the British Civil Contingencies Act. By carrying out an LCLIP, British local authorities can comply with the requirements in the National Indicator NI 188, which is designed to measure how well local authorities are

*Corresponding authors: Annika Carlsson-Kanyama, Swedish Defence Research Analysis, 16490, Stockholm, Sweden, Tel: 4685550 3955; E-mail: carlsson@foi.se

Received August 10, 2013; Accepted February 25, 2014; Published March 05, 2014

Citation: Kanyama AC, Blennow K (2014) Evaluating the Local Climate Impacts Profile Tool for Assessing Local Impacts of Extreme Weather Events. J Geogr Nat Disast 4: 122. doi:10.4172/2167-0587.1000122

Copyright: (c) 2014 Kanyama AC, et al. This is an open-access article distributed under the terms of the Creative Commons Attribution License, which permits unrestricted use, distribution, and reproduction in any medium, provided the original author and source are credited. 
assessing and addressing the risks and opportunities of a changing climate [20]. This indicator is designed to be a key driver for local action on adaptation to climate change, and progress is measured via self-assessment within each local authority, reporting a level of preparedness they have reached from level 0 to level 4 (ibid.). Typically, an LCLIP can be carried out within 11 weeks of working time by one person [8].

On the LCLIP website [21], information on 10 case studies is available (about one page each). The intended use of the LCLIP results from these cases is briefly mentioned, for instance it is intended to be used as a starting point for a comprehensive risk assessment under level 2 of NI188 (Hampshire, Sheffield, Manchester), as input for a climateproofing template developed for a sustainability appraisal (Leeds), or as input for a risk assessment for the local authority (Cardiff). Judging from the information on the LCLIP website, each LCLIP is tailored to the municipality in question. Some but not all studies have included a media trawl, for example, and some but not all have included interviews. Some of the LCLIPs were carried out by students, some by external researchers and some by the municipal officers themselves.

Although results from 10 case studies are available [21], no evaluation of the method has so far been described in the literature.

The aim of this study was to evaluate LCLIP with respect to transferability for use outside of the U.K. as well as its usefulness. The evaluation is based on experiences from applying the tool in three municipalities in Sweden as well as a systematic evaluation based on interviews with civil servants in the respective municipalities. With respect to transferability we wanted to know to what extent the LCLIP instructions [8] could be applied and regarding usefulness we wanted to know if civil servants in the selected municipalities found that LCLIP could be a "catalyst to further awareness and action on preparing for the future climate" [22].

\section{Materials and Methods}

\section{Local climate impacts profile (LCLIP) in the UK}

The procedure for performing an LCLIP includes the following four steps (UKCIP, 2009) [8]:

Project planning: Includes presenting the purpose of the LCLIP (e.g. can be "take a first step into adaptation activity") to officers in the organisation, the scope (e.g. geographical area or how far back in time information will be collected), the outputs (e.g. a report) and the personnel available. The advice from UKCIP [8] is to form a crossdepartmental group during this stage.

Building a database: Building a database about extreme weather events, impacts and responses. This can be compiled in a spreadsheet and information can be found in the local media (media trawl) or departmental records about e.g. emergency responses to weatherrelated incidents, or other departmental information related to this, such as costs and disruption time.

Data analysis: Includes summarising the spreadsheet data and interviewing relevant local authority officers about issues such as events, costs, significance and responses.

Outcomes and an agenda for further work: Includes sharing findings with relevant officers, producing LCLIP outputs and sharing messages, and circulating a summary report.

\section{Evaluating LCLIP's transferability outside the UK}

The Swedish Commission on Climate and Vulnerability (CCV) concludes that Sweden will be strongly affected by climate change and that adaptation to climate change should start already today and include increased preparedness for a rising sea level and extreme weather events such as heat waves and intense precipitation [23]. In Sweden, the municipalities are responsible for climate change adaptation at the local level [23]. In many municipalities, planning for adaptation has recently started and there is an urgent need for tools and guidelines to facilitate this adaptation [24].

The introduction and evaluation of LCLIP formed part of the research programme Climatools, where tools and methods for climate adaptation at the local level in Sweden were developed in collaboration with municipalities. Documentation of other tools and methods than LCLIP can e.g. be found in Baard et al. [25] and Mossberg et al. The LCLIP tool was selected because of its relative simplicity as the researchers discovered that many Swedish municipalities were not very aware of the needs for climate change adaption when the programme started (2007) and thus needed a tool that could catalyst such awareness and also action.

The introduction and evaluation of LCLIP was carried out in collaboration with the Swedish University of Agricultural Sciences (SLU) in Alnarp. During a seminar (autumn 2009), LCLIP was presented as a potential tool for municipalities in Sweden based on the experiences from Great Britain, and it was announced that volunteer municipalities were being sought in Scania, southern Sweden. Burlöv and Landskrona municipalities expressed an interest almost immediately after that seminar, while Lomma was recruited by the 'snowball effect'. Some characteristics in the municipalities are shown in Table 1.

In Lomma and Burlöv, the municipalities were asked to form a cross-departmental working group that would act as a steering group and recipient for the LCLIP, to arrange a half-day introduction session for students from SLU to carry out the LCLIP, to provide a list of people to interview, and to host a seminar in the municipality when the LCLIP was completed. The researchers emphasised that the crossdepartmental group should include representatives not only from 'technical' departments such as those responsible for roads, water and sewage and emergency response, but also from the care sector. The reason for Burlöv carrying out an LCLIP was because they needed an activity to start off adaptation work in the municipality and also needed the results as input for their planning process. In Lomma, adaptation work had already started by making a flooding map of the coastline, but LCLIP was seen as a good complement. The LCLIPs in Lomma and Burlöv were performed in spring 2010 by students from SLU (the students were involved in only case each) and included all four steps listed above, using the LCLIP manual as a guideline [8]. The students were supervised and instructed about methods for the media trawl and the interviews and presented their results at the seminars organised by the municipalities. They also wrote a report on each case [26-28]. In Landskrona, a cross-departmental group dealing with adaptation to climate change already existed when the LCLIP started, although it had not worked extensively, and the LCLIP process was in fact seen

\begin{tabular}{|c|c|c|c|c|}
\hline Municipality & $\begin{array}{c}\text { Inhabitants } \\
(\mathrm{n})\end{array}$ & $\begin{array}{c}\text { Land area } \\
\left(\mathrm{km}^{2}\right)\end{array}$ & $\begin{array}{c}\text { Length of } \\
\text { coastline }(\mathrm{km})\end{array}$ & $\begin{array}{c}\text { Height above sea level, } \\
\text { main urban settlement } \\
(\mathrm{m})\end{array}$ \\
\hline Burlöv & 17,000 & 19 & 1.4 & $3-10$ \\
\hline Landskrona & 40,000 & 141 & 18 & $1-10$ \\
\hline Lomma & 22,000 & 56 & 13 & $1-15$ \\
\hline
\end{tabular}

Table 1: Some characteristics of the three municipalities Burlöv, Landskrona, and Lomma. 
as a good means of initiating adaptation activities in the municipality. All the steps in the LCLIP [8] were also carried out in Landskrona but by an employee from the municipality (for the media trawl) and by a researcher (for the other steps). In Landskrona too, it took some convincing for the municipality to add members from departments dealing with care and schooling to the existing group of representatives from mainly the technical side. The Landskrona LCLIP was reported at a seminar and the municipality also issued a report of its own on the LCLIP results $[29,30]$. Table 2 shows the number of students, researchers and civil servants who were involved in the application of the LCLIP and also the number of female civil servants involved.

Finally, in a workshop where notes were taken, the students who conducted the LCLIPs in Burlöv and Lomma shared their experiences about how smoothly the various steps in the LCLIP manual could be applied. In Landskrona, the civil servant who did the media trawl was interviewed with notes taken, and the researcher who carried the other steps in the LCLIP took notes of her own impressions.

Usefulness towards meeting the goal of being a catalyst to further awareness and action on preparing for the future climate

The usefulness of LCLIP for meeting the goal of being a catalyst to further awareness and action was evaluated based on interviews with municipality civil servants well informed about the results in their own municipality. Representatives from the municipal authorities were interviewed twice, the first time per telephone immediately (less than one month after) after the LCLIP had finished and a second time, in person 18-24 months after the LCLIP was applied. The first interviews were carried out by the researchers and the second ones by a consultant [26] to avoid bias when asking for a judgement of usefulness about LCLIP. All those interviewed the second time were also interviewed during the first time. Notes were taken during all interviews. Table 3 gives some details about the two sets of interviews.

The following question was posed in each municipality on both occasions:

What are, in retrospect, your impressions of the result from the LCLIP?

The interviewees were then asked to be specific about the contribution to new knowledge on local weather impacts and vulnerability, better understanding of how different departments work and if the LCLIP had stimulated new thoughts about adaptation to climate change.

The second interview included also the following question:

How useful has LCLIP been to the municipality?

Here, we investigated at some length if the LCLIP results had raised awareness of weather impacts and had been included in comprehensive planning or risk analysis.

\begin{tabular}{|c|c|c|c|c|}
\hline Municipality & $\begin{array}{c}\text { Number of } \\
\text { students }\end{array}$ & $\begin{array}{c}\text { Number of } \\
\text { researchers }\end{array}$ & $\begin{array}{c}\text { Number of } \\
\text { civil servants }\end{array}$ & $\begin{array}{c}\text { Number of women } \\
\text { female civil } \\
\text { servants }\end{array}$ \\
\hline Lomma & 4 & Only as backup & 10 & 5 \\
\hline Burlöv & 3 & Only as backup & 7 & 3 \\
\hline Landskrona & 0 & 1 & 17 & 6 \\
\hline
\end{tabular}

Table 2: Number of students, researchers and civil servants involved when applying the LCLIP.

\begin{tabular}{|c|c|c|c|c|}
\hline Municipality & \multicolumn{2}{|c|}{ First interview } & \multicolumn{2}{c|}{ Second interview } \\
\hline & Number of officers & $\begin{array}{c}\text { Number of } \\
\text { researchers }\end{array}$ & Number of officers & $\begin{array}{c}\text { Number of } \\
\text { consultants }\end{array}$ \\
\hline Lomma & 1 (a woman) & 1 & 1 (a woman) & 1 \\
\hline Burlöv & $\begin{array}{c}3 \text { (one woman, two } \\
\text { men) }\end{array}$ & 1 & $\begin{array}{c}\text { (one woman, one } \\
\text { man) }\end{array}$ & 1 \\
\hline Landskrona & 1 (a man) & 1 & 1 (a man) & 1 \\
\hline
\end{tabular}

Table 3: Number of researchers, consultants and officials involved when interviewing officials about how LCLIP met the goals.

\section{Results}

\section{Evaluating LCLIP's transferability outside the UK}

Overall, the process description for the LCLIP described in UKCIP [8] worked well in the three Swedish municipalities in which LCLIP was applied, although a range of issues arose that needed to be resolved during the course of the work. In some cases these led to deviation from the LCLIP instructions.

The LCLIP manual stipulates that a cross-departmental working group should be formed in order to perform the LCLIP in its first stage, which includes scoping and delimitation. Elderly people and children may be especially vulnerable to heat [31], which means it is important to include 'soft' departments and not only the departments responsible for sewage and drinking water, streets and emergency responses. As mentioned above, it took some convincing of the municipal authorities to ensure that representatives from all departments, even among those in charge of elderly care, schools and kindergartens, were part of both the group that steered the LCLIP and those interviewed. This worked rather well and as a result the consequences of heat waves were placed on the agenda in municipalities where inundation due to heavy rain events and rising sea level was previously the main focus when appraising the negative impacts of extreme weather events. This also made women part of the weather-related discourse in the municipal authorities in a more prominent manner than before, as the civil servants working with elderly care and schooling are predominantly female, while staff in the technically orientated departments are predominantly male. As an example, in Landskrona, out of 17 civil servants interviewed, six were women; five from the Care Department and one from the Environmental Department. All interviewees from the departments dealing with Recreation, Sewage and Water, Rescue and Construction were male $[29,30]$.

Completing the media trawl in the second stage of the LCLIP process proved possible, although some complications occurred in the two municipalities that did not have their 'own' local newspaper, Lomma and Burlöv. These two municipalities can be considered suburbs of Malmö, the municipality with the largest population in the county in which the four case study municipalities are located. In these municipalities various newspapers were used during the media trawl, such as the regional newspapers (Skånska Dagbladet and Sydsvenskan) and the now common free local papers that are distributed in public spaces and get their income only from advertisers. However, the news coverage of the municipalities in question was poor in these free papers and in the end, news items in regional papers relating to Malmö were used as a substitute for some local information. Very few articles in any newspaper contained information about the costs of extreme weather events, something that the LCLIP manual mentions as important information. However, it was possible to collect information about the magnitude of the events (such as amount $(\mathrm{mm})$ of precipitation on a specific occasion), the impacts in qualitative terms (number of roads flooded), the response measures (such as pumping) and the 
department that carried out the measure (such as the rescue services). In the media trawls for all four municipalities there was very little, if any, information about the consequences of heat waves, but much information regarding inundation and precipitation, strong winds and snowfall. Regarding measures taken to cope with flooding, strong winds and heavy snow, those reported in the media were mainly of a technical nature (pumping, felling trees, towing cars and snow-ploughing) and very little was reported about changes in organisations and behaviour.

When it came to using municipal records during the second stage of the LCLIP process, this was only done in Landskrona. It has its own rescue service that has managed to produce material which differentiates between weather type (rain, storm, snow) and measures applied. However, neither these sets of records contained data about number of working hours, costs or reputation repercussions, something asked for in the LCLIP manual.

The interviewees approached during the third stage of the LCLIP were selected by the respective municipal authorities. In order to collect good information at this stage, we discovered that great care had to be taken to get the 'right' informants, so as to strike a balance between 'old' civil servants with a long service record but a somewhat failing memory and younger employees with a good memory but few years in service. Another challenge when choosing interviewees was to find civil servants at the right level in the organisation: at too high a level they did not know enough detail about the day-to-day work to have interesting information, while at too low a level they did not have the necessary overview of problems occurring in the organisation. A striking example of the importance of finding informants at the right level in the organisation occurred in Landskrona, where the director of social services strongly asserted that her department had never experienced problems during heat waves, but the manager of care homes for the elderly in the same municipality gave numerous examples of problems during heat waves and adaptation measures, including relocating the elderly from the top floor and keeping a stock of fans for hot days. We found no mention about such intricacies in the LCLIP manual.

In interviews, the LCLIP manual suggests using the database of extreme weather events to initiate conversations about those specific events, in order to gather more information about each of them, such as costs and impacts on reputation. In an attempt to follow these LCLIP instructions we sent the database constructed during the second phase and its analysis to the interviewees beforehand. However, we discovered when the interviews started that very few of the respondents had looked in detail at this material due to time constraints and that even after being reminded of specific days during which e.g. rains were heavy, the sea was high or winds were strong, the interviewees did not remember them clearly and could not discuss any specific measure or impacts during those dates. Instead, we posed questions as: Do you remember any time when you had heavy rains/winds/a long heat wave/high sea level that caused problems in the municipality and what happened and how did you respond? This worked quite well when the respondents were given some time for thought, but they nevertheless found it difficult to connect any costs to such events and confirmed that no reporting system for this existed in their municipal authority. An exception to the rule was a heavy rain event in July 2007, after which several municipal authorities evaluated their costs of insurance claims due to flooding of private property.

During the interviews in Landskrona, we included questions about observed changes in weather patterns, as this came up spontaneously during the first interviews in that municipality. We also included questions about possible adaptation options for various extreme weather events assuming that these would increase/become more serious, and included those in the Landskrona report. While doing this, we refrained from talking much about climate change, as recommended by the LCLIP manual, and focused only on extreme weather events that are already occurring. During some interviews we discovered in fact that some respondents were doubtful about whether climate change was occurring or not $[17,18]$, something that we later found to be true for one in 10 municipal directors and politicians [29]. Therefore we believe the advice in the LCLIP manual to be useful even in forthcoming work, but we also believe that talking about possible adaptation options not yet implemented in the municipalities and making a list of them may be a good start for further adaptation work based on local knowledge only.

The presentation of the LCLIP (the fourth step) to the four municipal authorities included a seminar for selected civil servants and politicians from these municipal authorities and a report. Other modes of communication such as press releases or public seminars [8] were not used, the reason appearing to be that the municipal authorities were not accustomed to such methods and did not feel comfortable trying them out. In addition, convincing politicians to attend these seminars was not easy, as they were conducted during day time when most local politicians are not available and also do not receive an allowance for attending such meetings.

\section{Usefulness towards meeting the goal of being a catalyst to further awareness and action on preparing for the future climate}

Impressions in retrospect about of the result from the LCLIP: In the interviews with staff from the four municipalities immediately after the LCLIPs had been completed, two out of three municipalities (Burlöv and Landskrona) agreed that the overall impression of the LCLIP was good and that the material was useful because it gave a good overview of the considerable amount of impacts of extreme weather events, which they otherwise did not have. The results from interviews were particularly appreciated and staff from Burlöv and Landskrona municipalities emphasised the need to get key personnel for those, meaning people who have been in the municipal authority for a long time. The spreadsheet was also appreciated, as it allowed impacts to be coupled to adaptation actions in a manner that made it very concrete to the municipal authorities what they can do by themselves. Burlöv and Landskrona also emphasised that the presentations should focus on the impacts and actions in the municipalities and not so much on impacts in general. Both Burlöv and Landskrona saw the LCLIP being used as input in their comprehensive plan or as a first chapter in an adaptation plan. All in all, these two municipalities felt satisfied and would recommend the LCLIP method to other municipalities for obtaining interesting material with a relatively small work input. In Lomma the evaluation was less positive, owing to the fact that its municipal authority had already started climate change adaptation work and that the LCLIP added little new knowledge. However, Lomma would still recommend the method to other municipal authorities starting climate change adaptation work and thought that the results could be used in a future adaptation plan.

During the second interview [26] the interviewed civil servant in Landskrona still thought that LCLIP was a good an well-structured method that gained attention also among civil servants that do not work with environmental issues and city planning and that LCLIP thereby stimulated adaptation work among those not normally concerned with climate change. Also Burlöv was positive about the LCLIP pointing at its efficiency in compiling the impacts of extreme 
weather events. In Lomma the review of newspaper articles (media trawl) was particularly appreciated as a method for bringing memories and experiences from past weather events to life. With regards to new knowledge, all municipalities agreed to that LCLIP did not provide a lot of such knowledge, but rather a good overview of impacts already known and a platform for further work. When it comes to a better understanding of how different departments in the municipality work the LCLIP did not contribute with much as such understandings were already present in the three municipalities. With regards to evoking thoughts about climate change adaptation Landskrona thought that LCLIP evoked thoughts about the impacts of events such as flooding and heat waves in the municipality while the other municipalities gave vague answers to this question.

The usefulness of the LCLIP to the municipalities: The interviews in March 2012 [26] revealed that adaptation work had since the time of the LCLIP proceeded in different directions and at different paces, but there were many similarities in how the LCLIP was judged. Concerning the extent to which the adaptation planning had proceeded after finishing the LCLIP, all municipalities had advanced it in the year that followed the LCLIP process:

Landskrona now included climate adaptation in its planning "to a considerable degree" and adaptation consideration was now part of the updated version of its comprehensive plan. In Lomma, a storm in November 2011 had a considerable impact, with inundation of builtup areas, and as a result there were now plans for existing barriers to be raised and for climate change adaptation work already initiated to be continued. In Burlöv, where adaptation work started off with the LCLIP, the provision of water and sanitation had now been reorganised, with greater access to expertise in a new organisation. In addition, all areas lower than $3 \mathrm{~m}$ above sea level had been mapped and the next step was to conduct more in-depth studies of those, as well as studies of how green areas could be used to mitigate heat.

The role of LCLIP was now expressed as a good incitement and platform for gathering relevant municipal actors where some discovered that they had reasons to think about adaptation to climate change. The civil servants from the municipalities confirmed that LCLIP had contributed to raising awareness about adaption (Landskrona and Lomma) and that it became an input to the comprehensive plan (Burlöv).

\section{Discussion}

The overall results from this study, where LCLIP was evaluated through applying it in three Swedish municipalities and complementing interviews, are that the instructions given for conducting LCLIP [8] could be followed, albeit with some modifications, and LCLIP can be a catalyst to further awareness and action on preparing for the future climate albeit with some reservations when it comes to municipalities already engaged in adaptation work. Because of this we encourage further use and evaluation of LCLIP, especially for communities that have not yet started adaptation work.

Some important lessons can be gained from applying the LCLIP tool in Sweden. First, even if LCLIP, or similar approaches, are comparatively cheap tools to use and the records are fairly easy to keep, none of the Swedish case municipalities kept a detailed record of local weather impacts to facilitate climate-related planning for the future. LCLIP and related approaches can be considered primarily as a tool for "beginners" in municipal climate change adaptation work and the lack of use reflects the early stage at which Swedish municipalities find themselves with respect to systematic climate change adaptation.
Second, the comparatively low cost of implementing and maintaining a record of local weather impacts makes the tool useful also in poorer countries where inexpensive tools such as LCLIP might be one of few options available. However, the complexity and costs that will be incurred even in planning for climate change adaptation (let alone implementing measures) should not be underestimated and no one tool can provide a quick fix for any local society. After implementing LCLIP, local authorities in Sweden and other rich countries have the economic capacity to take further steps in the adaptation process with other, more costly investigations, such as detailed mapping of the topography and simulation of effects of future sea levels and flooding. Research and development is needed to provide new and systematically tested adaptation tools in this respect too.

Third, through measures for including "soft" departments in the work, the LCLIP tool provides the opportunity to take into account often neglected groups in assessments of vulnerability to climate change. Issues relating to inequality with respect to gender are well represented in the literature on adaptation in developing countries [32]. However, there is reason believe that women may be more severely affected by climate change than men even in developed countries, although the adaptation literature has devoted little attention to this issue so far [33]. As we show in this present study, the broad approach of LCLIP, where representatives from all departments in the local authority are encouraged to participate in the vulnerability assessment, brings different issues to the table, e.g. relating to the documented sensitivity to heat among elderly people, many of whom are women [32]. However, vulnerability assessments often focus on how to use various technical measures such as pumps, chainsaws and excavators, and social care issues are often not raised. Furthermore, the focus in LCLIP is on measures related to change in organisation and behaviours that have occurred due to extreme weather events, which means that women's experiences of dealing with extreme events are taken into account. Even in a comparatively gender-equal country such as Sweden, men are predominantly involved in any issue that requires technical skills, while women to a large extent dominate in the caring and administration professions.

Our fourth and last point is that evaluation of tools and methods for climate change adaptation would benefit if the users and those intended to benefit from the results of using the tools were to be included in a systematic way to a larger extent than now, and if the results were to be reported in the literature. In that regard the present study paves the way, since it used an existing tool that had not previously been systematically evaluated and assessed it on the basis of experiences from applying it in three Swedish municipalities. It seems that such evaluations, although time-consuming and laborious, would increase the understanding of local opportunities to adapt, providing much needed knowledge as climate change proceeds.

\section{Conclusions}

In this study, the British climate adaptation tool Local Climate Impacts Profile (LCLIP) was evaluated for the first time. The overall conclusion from applying the tool in three Swedish case study municipalities was that the results received a positive response from municipal civil servants and that the tool can be applied in Swedish municipalities after some minor adjustments. In at least two of the three case municipalities, the LCLIP process seemed to have encouraged further work on climate change adaptation, as was the intention.

\section{Acknowledgements}

The authors wish to thank the officers in Burlöv, Landskrona, and Lomma 
Citation: Kanyama AC, Blennow K (2014) Evaluating the Local Climate Impacts Profile Tool for Assessing Local Impacts of Extreme Weather Events. J Geogr Nat Disast 4: 122. doi:10.4172/2167-0587.1000122

municipalities for their participation and support in the LCLIP, students at the course Landscape in transition - impacts and adaptation to climate change (Swedish University of Agricultural Sciences, Alnarp) in 2010 for carrying out the LCLIP in two of the three municipalities, and the Swedish Environmental Protection Agency (research programme Climatools) and the Swedish Foundation for Strategic Environmental Research (research programme Mistra-SWECIA) for financial support.

\section{References}

1. World Bank (2012) Turn Down The Heat. Why a $4^{\circ} \mathrm{C}$ Warmer World Must Be Avoided. A Report for the World Bank by the Potsdam Institute for Climate Impact Research and Climate Analytics.

2. Burton I (2004) Climate Change and The Adaptation Deficit. Occasional Paper No 1, Adaptation and Impacts Research Group, Meteorol. Service of Canada, Environment Canada, Toronto.

3. Smit B, Wandel J (2006) Adaptation, Adaptive Capacity, and Vulnerability. Global Environ Change 16: 282-292.

4. Hanak E, Lund JR (2012) Adapting California's Water Management to Climate Change. Climatic Change 111:17-44.

5. Shepard CC, Agostini VN, Gilmer B, Allen T, Stone J et al. (2012) Assessing Future Risks: Quantifying The Effects of Sea Level Rise on Storm Surge Risk For The Southern Shore of Long Island, New York. Natural Hazards 60: 727745

6. Spickett JT, Brown HL, Katscherian D (2011) Adaptation Strategies for Health Impacts of Climate Change in Western Australia: Application of Health Impacts Assessment Framework. Environmental Impacts Assessment Review 31: 297 300

7. Baard P, Johansson MV, Carlsen H, Björnberg KE (2012) Scenarios and Sustainability: Tools for Alleviating the Gap Between Municipal Means and Responsibilities in Adaptation Planning. Local Environment 17: 641-662.

8. UKCIP, United Kingdoms Climate Impacts Programme (2009) A Local Climate Impacts Profile: How To Do and LCLIP. UKCIP, Oxford, UK.

9. UKCIP, United Kingdoms Climate Impacts Programme (2012a). Information Available from http://www.ukcip.org.uk/tools/ $27^{\text {th }}$ of December 2012.

10. UNFCC (2012) Compendium on Methods and Tools to Evaluate Impacts of and Vulnerability and Adaptation To, Climate Change.

11. Holsten A, Kropp JP (2012) An Integrated and Transferable Climate Change Vulnerability Assessment for Regional Application. Natural Hazards Journal of The International Society for The Prevention and Mitigation of Natural Hazards, Journal of The International Society for The Prevention and Mitigation of Natural Hazards, DOI 10.1007/S11069-012-0147-Z.

12. Dai X, Jia, Gensuo J, Mcevoy D, Neufeldt H, Serra A (2010) The Climate Learning Ladder. A Pragmatic Procedure to Support Climate Adaptation. Environmental Policy and Governance 20:1-11.

13. Debels $P$, Szlafsztein $P$, Aldunce $C$, Nari $Y$, Carvajal $Y$, Queintero-Angel $M$, Celis A, Bezanilla A, Martinez D (2009) IUPA: A Tool For The Evaluation Of The General Usefulness of Practices for Adaptation to Climate Change and Variability. Natural Hazards 50:211-233.

14. Jonsson AC, Hjerpe M, Sköld YA, Glaas E, Andre K, Simonsson L (2012) Cities 'Capacity to Manage Climate Vulnerability: Experiences from Participatory Vulnerability Assessments in The Lower Göta Älv Catchment, Sweden. Local Environment 17: 735-750.

15. Albert C, Zimmerman T, Knieling J, Von Haaren C (2012) Social Learning Can Benefit Decision-Making in Landscape Planning: Gartow Case Study On Climate Change Adaptation, Elbe Valley Biosphere Reserve. Landscape and Urban Planning 105:347-360.

Citation: Kanyama AC, Blennow K (2014) Evaluating the Local Climate Impacts Profile Tool for Assessing Local Impacts of Extreme Weather Events. J Geogr Nat Disast 4: 122. doi:10.4172/2167-0587.1000122

This article was originally published in a special issue, Environment and Health handled by Editor(s). Dr. Kevin A Henry, Kent state University, USA
16. Blennow K, Persson J, Tomé M, Hanewinkel M (2012) Climate Change: Believing and Seeing Implies Adapting. PLOS ONE 7:E50181.

17. Blennow K, Persson J, Wallin A, Vareman N , Persson E (2013) Understanding Risk in Forest Ecosystem Services: Implications for Effective Risk Management, Communication And Planning. Forestry.

18. Blennow K, Persson J (2009) Climate Change: Motivation for Taking Measure to Adapt. Global Environmental Change 19:100-104.

19. UKCIP, United Kingdoms Climate Impacts Programme.

20. LRAP, The Local and Regional Partnership Board (2008) Adapting to Climate Change. Guidance Notes for MI 188. Version 1.6, 19 December 2008.

21. UKCIP, United Kingdoms Climate Impacts Programme.

22. UKCIP, United Kingdoms Climate Impacts Programme.

23. CCV, The Commission on Climate and Vulnerability (2007) Sweden Facing Climate Change - Threats and Opportunities. SOU 2007:60 Ministry of Environment, Stockholm.

24. SKL, Swedish Association of Local Authorities and Regions (2009) Läget I Landet: En Undersökning Om Klimatanpassning I Den Fysiska Planeringen. Stockholm.

25. Sonnek KM, Johansson B, Lindgren J (2013) Risk and Vulnerability Analysis: A Feasible Process for Local Climate Adaptation in Sweden? Local Environment 18: $781-800$

26. Olsson H (2012) LCLIP Intervjuer: Uppföljning Av Projekt Mellan FOI Climatools Och SLU. Ramböll.

27. Arvidsson A, Olsson H, Rumpunen E, Link M (2010) Adaptation to Climate Change. Case Study in Lomma. Final Report on the Course "Landscape in Transition, Impacts and Adaptation to Climate Change", SLU Alnarp.

28. Folkesson J, Galan P, Johnsen S (2010) Climate Assessment Tools for Burlöv Municipality. Final Report on the Course "Landscape in Transition, Impacts and Adaptation to Climate Change", SLU Alnarp.

29. Kanyama AC, Friberg LH (2012) Kommunpolitikers Och Kommunchefers Syn På Klimatförändring Och Anpassningsbehov. Resultat Från En Enkätundersökning. FOI-R-3441-SE.

30. Kanyama AC, Nordell O, Lindahl M (2010) Konsekvenser Av Besvärligt Väder Landskrona En Lokal Klimateffektprofil - Ett Utkast. Landskrona Kommun Och FOI.

31. Rocklöv J, Forsberg B (2010) The Effect of High Ambient Temperature on the Elderly Population in Three Regions of Sweden. Int J Environ Res Public Health 7 .

32. Hemmati M (2005) Gender and Climate Change in The North: Issues, Entry Points and Strategies for Post-2012 Process and Beyond. Report Prepared for Genanet -Focal Point Gender Justice and Sustainability, Frankfurt, Germany.

33. Björnberg KE, Hansson SO (2012) Integrera Genus I Klimatanpassningen Vägledning Och Råd För Det Kommunala Klimatarbetet. FOI-R--3405-SE.

Submit your next manuscript and get advantages of OMICS Group submissions

Unique features:

- User friendly/feasible website-translation of your paper to 50 world's leading languages Audio Version of published paper

Digital articles to share and explore

Special features:

350 Open Access Journals

30,000 editorial team

21 days rapid review process

Quality and quick editorial, review and publication processing

Indexing at PubMed (partial), Scopus, EBSCO, Index Copernicus and Google Scholar etc

Sharing Option: Social Networking Enabled

Authors, Reviewers and Editors rewarded with online Scientific Credits

Better discount for your subs

Submit your manuscript at: www.omicsonline.org/submission/ 